\title{
Samuel Richardson's
}

Fictions of Gender 



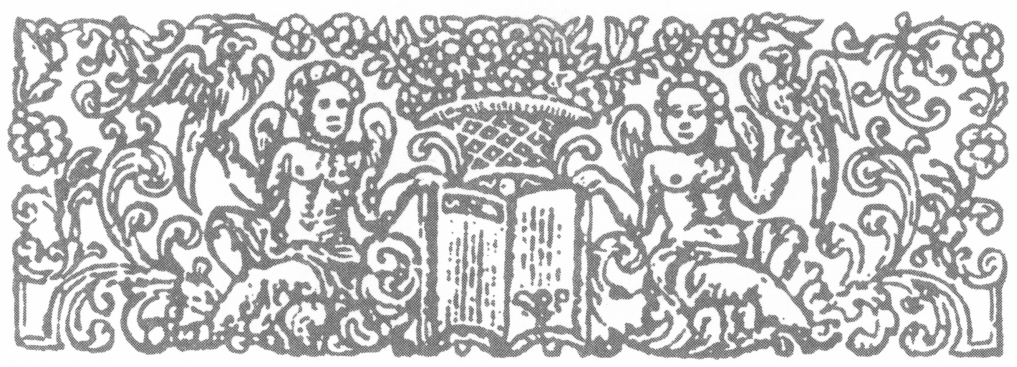

\title{
Samuel Richardson's
}

\section{Fictions of Gender}

\author{
TASSIE GWILLIAM
}

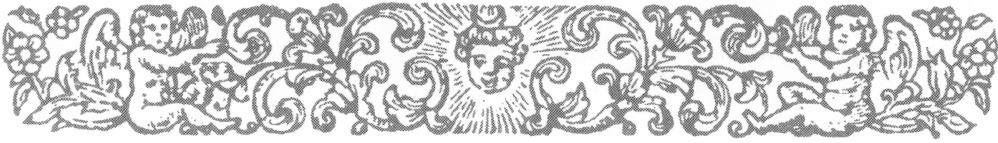

STANFORD UNIVERSITY PRESS

STANFORD, CALIFORNIA 


\section{Stanford University Press \\ Stanford, California}

(C) 1993 by the Board of Trustees of the

Leland Stanford Junior University

Printed in the United States of America

Original printing 1993

Last figure below indicates year of this printing:

$\begin{array}{llllllllll}04 & 03 & 02 & \text { OI } & 00 & 99 & 98 & 97 & 96 & 95\end{array}$

CIP data appear at the end of the book

Stanford University Press publications are distributed exclusively by Stanford University Press within the United States, Canada, and Mexico; they are distributed exclusively by Cambridge

University Press throughout the rest of the world. 
To Frank Stringfellow

\&

Nicholas Gwilliam Stringfellow 
